Preparing and Implementing a Task-based ESL Curriculum in an EFL Setting: Implications for Theory and Practice

Elizabeth Gatbonton and Guijing Gu

Current knowledge about curriculum development $(\mathrm{CD})$ comes into sharper focus when viewed in the light of experiences gained from developing curricula in different settings. The more distinct the new setting is from previous $\mathrm{CD}$ sites, the more interesting the perspective gained about this knowledge. In this paper we discuss a CD project set in Beijing, China. The challenges posed by developing curriculum in this unique setting are numerous. Foremost are those arising from having to negotiate a workoriented English as a Second Language (ESL) curriculum acceptable to two groups of teachers with different cultural and professional backgrounds who must not only raise the proficiency level of heterogeneous groups of learners in a short period of time but must also participate in an exchange of skills program involving the new curriculum.

Current knowledge about curriculum development (e.g., Johnson, 1989; Nunan, 1988; Yalden, 1987) comes into sharper focus when viewed in the light of experiences gained from developing curricula in different settings. The more distinct the new setting is from previous $\mathrm{CD}$ sites, the more interesting the perspective gained about this knowledge (e.g., Prabhu, 1987; Tanachanan, 1983). In this paper we discuss a $C D$ project set in China; namely, the $C D$ project at the Canada-China Language Centre or CCLC, for short. The CCLC is a Canadian International Development Agency (CIDA)funded language training Centre in Beijing, jointly administered by Saint Mary's University (Halifax) and Beijing Normal University (Beijing). For three years since 1989, we both served as curriculum consultants for the Centre with the mandate to design the curriculum for its English language teaching program and develop support materials for it.

The challenges posed by $C D$ in this setting are numerous. First and foremost are those arising from having to negotiate a workoriented, English as a Second Language (ESL) program in a setting more appropriate for teaching English as a Foreign Language (EFL) program. The program's ESL character comes from its mandate to teach English as a primary tool for communication to Chinese professionals and scientists when they are in Canada training in its scientific and educational institutions. But, the teaching itself must be conducted in China, where there is very little 
support for the use of English outside the classroom. Secondly, the program is funded by CIDA, Canada's official development aid agency and so the Canadian and Chinese teachers in the program had the dual task of teaching and participating in a transfer of skills program to ensure that one group (the Chinese) could take over after the other (Canadians) leaves. Thirdly, although the language program is work oriented-it aims to teach language for work and professional related matters-its students come from different disciplines (e.g., ranging from medicine to translation) and lack the homogeneity expected in usual work-oriented programs. Finally, the students start out each term with different levels of English proficiency, (albeit all within the intermediate range); yet all must attain their target proficiency in only one, fifteen-week term.

In this paper, we describe, first, the major $C D$ problems we dealt with. Then, we describe the salient features of the curriculum we finally developed. Finally, we highlight a few general $C D$ issues and discuss how these related to the specific $C D$ problems we encountered. In these discussions, we will use the term curriculum to refer only to the formal teaching of English. We exclude reference to other activities (e.g., English Corner, Thursday Lectures) that were subsumed under this term in our final $C D$ report (Gatbonton \& $\mathrm{Gu}, 1991)$. In that report, we used curriculum development in its broadest sense to include Johnson's (1989) planning, ends/means justification (specifying objectives and choosing methodology), program implementation (materials design), classroom implementation (teacher training), and evaluation stages. Syllabus will be used to refer to the specific program developed for each course.

\section{DESIGNING THE CURRICULUM}

Main Problems: Right from the beginning, we were concerned with five problem areas. These were: 1) Course distribution: Should there be a separate course for each of the four skill areas? Or, should there be only one, focusing on all these skills at once? 2) Language and content: How should each course handle the relationship between language and content (Mohan, 1986)? Should the course emphasize language, content, or both? 3) Pedagogical concerns: Should classroom activities be organized around themes, functions, tasks, or structures? 4) Washback effect of the test: How much of the curriculum should be sensitive to preparing the students to pass the Canadian Test for Scholars and Trainees (CanTEST), the exit test for all prospective trainees to Canada 
(Des Brisay, 1991)? 5) Methodology: Would a communicative approach be suitable? If so, what form should it take?

Organizing the $\mathrm{CD}$ Team: Preliminary negotiations about the curriculum (Gatbonton, 1990) made clear that any CD team we put together should reflect the full involvement of the Chinese. Chinese involvement was essential not only because the Chinese constituted half of the teaching team but also because they would eventually to take over full management of the program. To attain this aim, we urged the creation of the post of a Chinese curriculum consultant with status equal to that of the Canadian curriculum consultant. Then, we carefully selected our $C D$ teams so that they would include more Chinese than Canadian members. Our skills teams (teams responsible for each of the four skill areas), for instance, each included only one (or 2) Canadian teachers to every 2 (or 3 ) Chinese teachers.

Curriculum Design Schedule and Procedure: Our curriculum development schedule encompassed two to three intensive six-toeight-week periods per year coinciding with the Canadian Curriculum Consultant's visits to China (Her position was designated Canadian-based). Within each period, 2-3 afternoons a week plus every other hour that could be carved out of the teachers' heavy teaching schedules were devoted to curriculum work.

The first CD period was dedicated to a series of theoretical workshops conducted to benefit both Canadian and Chinese members who had never participated in $C D$ before (November 1989). This was followed by another series (April 1990) in which the $C D$ teams helped articulate the general philosophy, aims, and approach of the CCLC curriculum and made final decisions about the taxonomy of tasks that the CCLC could handle. The nature, format, and characteristics of pedagogical tasks to implement the curriculum were also discussed. In subsequent periods (October 1990, February 1991), model lessons exhibiting these characteristics were constructed by volunteer teachers and were presented to the skill teams for comments and evaluation. Once a consensus was reached about the content and format of the lessons, the specifications were imparted to materials developers in Canada who prepared model modules based on them. In February 1991, the first set of revised model modules were brought back to China for further evaluation and field testing. During the evaluation period, feedback on each module was sent back to Canada so that appropriate revisions could be made. When enough modules had been 
revised and field-tested for the speaking and reading courses, partial implementation of the curriculum began (February 1992). With the completion of the listening and writing modules in August 1992, the full implementation of the curriculum was undertaken.

\section{THE CCLC CURRICULUM}

A complete description of the CCLC curriculum requires more space than allowed here so we describe only those features relating to its course distribution, syllabus organization, design of pedagogical tasks, and methodology. Table 1 below summarizes these characteristics:

TABLE 1

Characteristics of the Syllabus

\begin{tabular}{|c|c|c|}
\hline $\begin{array}{l}\text { In terms of course } \\
\text { distribution: } \\
\text { *Skill-focused }\end{array}$ & $\begin{array}{l}\text { In terms of syllabus design: } \\
\text { "Task-based } \\
\text { *Knowledge and skills- } \\
\text { integrated } \\
\text { *Non-graded but flexible }\end{array}$ & $\begin{array}{l}\text { In terms of the design of } \\
\text { pedagogical tasks: } \\
\text { *Modular } \\
\text { *Project-oriented } \\
\text { "Theme-based } \\
\text { *CanTEST-sensitive }\end{array}$ \\
\hline & $\begin{array}{l}\text { xt-adjusted Communicative } \\
\text { munication to formal instrue }\end{array}$ & $\begin{array}{l}\text { thodology } \\
\text { n Model) }\end{array}$ \\
\hline
\end{tabular}

\section{Course Distribution}

Skill-focused: Initially, all the courses at the CCLC were multiskills, i.e., they focused on the development of not one but two or more skills at once. However, to accommodate the Chinese teachers' wish that they handle only one skill area at a time, we changed the course distribution from multi-skills to skill-focused. In a skill-focused distribution, separate courses are held for each of the four skill areas. However, teaching each does not exclude the use of reading, listening, and writing activities, when these are deemed necessary and appropriate. 


\section{Syllabus Design}

To design each syllabus, we opted for a task-based, knowledgeand-skills integrated, and non-graded but flexible approach.

Task based: Long $(1985,1990)$ defines tasks as real world activities that the learners are likely to do in the L2. In our case, these are the basic speaking, reading, listening, and writing activities that the trainees are likely to have to do when they are in Canada; for example, write a $\mathrm{CV}$, discuss projects with their supervisors and colleagues, read journal articles, and listen to live lectures. We determined these tasks from various sources including program evaluation reports (Burnaby, Cumming \& Belfiore, 1986; Dionne, Cray, \& Huot, 1988), end-of-term reports, student evaluations and, of course, needs analyses reports (Chase \& Marshall-Smith, 1990; Martin \& Sun, 1987). We also consulted published papers on the academic needs of learners in North America similar to our trainees (Canseco \& Byrd, 1989; Horowitz, 1986; Johns, 1981; Ostler, 1980, to name a few). Finally, we took into account the intuitions of past and present teachers at the CCLC, whom we interviewed at various times during the $C D$ period.

In taking a task-based organizational focus, we rejected numerous other possible options. For example, since many of our students are in scientific fields (e.g., medicine, physics, engineering) we could have opted for an English for Science and Technology (EST) or English for Specific Purposes (ESP) syllabus design (see Hutchison \& Waters, 1987; Mackay \& Mountford, 1978). However, the lack of occupational and professional homogeneity of our clientele made this option unsuitable. We also rejected a general English syllabus design. To be effective, a general English course would have required more study time than the 15 or so weeks (one term) allowed our students by their work units.

Knowledge and skills-integrated: We opted for a syllabus design allowing the students not only to attain the linguistic skills they need but also the knowledge base required to ensure success during their Canadian sojourn. Past experience with Chinese trainees indicates that although most are practising scientists and professionals and carry out scientific investigations in the same manner as their North American counterparts do, there are enough differences in the interpersonal and work-related behaviour patterns of the two groups to cause problems. To minimize the opportunity for such problems to arise, we built into our syllabi mechanisms to help the students become aware of the cultural expectations of the new society in which they are to live and work. 
To attain the two-pronged goal of imparting language skills and knowledge skills, we designed each syllabus using a modified version of the language and content paradigm proposed by Mohan (1986). In the classic interpretation of this approach, (e.g., Brinton, Snow, \& Wesche, 1989; Snow, Met \& Genesee, 1989), content usually refers to a particular subject matter (e.g., the scientific concepts that the pupils must learn in their science course). In adult learning, content usually refers to an area in the learner's field of specialization (e.g., Graham \& Beardsley, 1986). However, because there was no one field common to all our students, we redefined content to mean knowledge of Canadian culture, in general, and of western scientific culture, in particular. Thus, in the syllabus for each course, we not only stated the tasks that the courses should focus on but also the specific rules and procedures that the students should know in order to carry out each task (specific knowledge), as well as the general background knowledge (including cultural) they need in order to understand the meaning, implications, and consequences of the task. We also presented the cognitive skills (e.g., how to classify information), the discourse skills and strategies (e.g., sequencing the information within an acceptable format), and the linguistic skills (ability to use capitalizations, italics, etc. in a formal document) that the person must develop in order to perform each task satisfactorily. Table 2 below presents an example of a task analyzed into its components.

Knowledge and skills-integrated also means that the procedure by which the students acquire this knowledge resembles the procedure employed when expanding one's knowledge of the field. Thus, for the trainees to learn about Canadians and their particular concerns and ways of thinking, they participate in activities requiring them to gather, classify, and synthesize information about these issues just as they would when they study and/or work in Canada. A module called Class Profile (Gatbonton, 1992) illustrates this point. In this module, the students' task is to prepare a profile of their class (e.g., who the students are, their fields, background) that can be compared to the profiles of previous classes. To prepare the profile, the students interview one another, pool the information they gather, then categorize and code them. Then, based on these data, they draw general statements to describe the class such as: The majority of the students in Class $A$ this term are female. Most are in the field of medicine. In this module then, both the content and the procedure (hence also the language) by which they learn this content are integrated towards one end. 
TABLE 2. Example of a Task Analyzed in Terms of its Knowledge and Skills Component

Task 3: Requesting Help

Borrow, return, order supplies and equipment using the telephone

\begin{tabular}{|c|c|c|c|c|c|}
\hline \multicolumn{3}{|c|}{ KNOWLEDGE COMPONENT } & \multicolumn{3}{|c|}{ SKTIS COMPONENT } \\
\hline & Spocific Knombodge & $\begin{array}{l}\text { Bectground Knowlodge } \\
\text { inctuding Culture }\end{array}$ & $\begin{array}{l}\text { Cognitive } \\
\text { shille }\end{array}$ & $\begin{array}{l}\text { Dinosurne } \\
\text { stille }\end{array}$ & $\begin{array}{l}\text { Linguizatic } \\
\text { Stirle }\end{array}$ \\
\hline 2. & $\begin{array}{l}\frac{\text { Knowledge of specific }}{\text { rules and procedures }} \\
\text { in: } \\
\text { Enquiring about trainece's } \\
\text { rights to office supplies } \\
\text { Enquiring about traince } \\
\text { access to equipment } \\
\text { (photocopier, computer) } \\
\text { Borrowingreturning } \\
\text { equipment and suppliea } \\
\text { Asking for help by } \\
\text { lelephone }\end{array}$ & $\begin{array}{l}\text { Knowlodge of: } \\
\text { Supplies and equipment } \\
\text { svailable to trainee use } \\
\text { Reaponsibilities towards } \\
\text { equipment } \\
\text { Artitudes towards } \\
\text { borrowing/returning } \\
\text { objects in North } \\
\text { American society. } \\
\text { Role of the telephone in } \\
\text { the Canadian Workplace. } \\
\text { Conventions in using the } \\
\text { telephone }\end{array}$ & $\begin{array}{l}\text { Ability to: } \\
\text { predict, direct, and } \\
\text { reorient the flow } \\
\text { of conversation }\end{array}$ & $\begin{array}{l}\text { Ability to: } \\
\text { use proper telephoning conventions } \\
\text { (e.g- greeting conventions, } \\
\text { summons-response corventions, } \\
\text { closing conventions) } \\
\text { uec oorrect adjacency pairs for } \\
\text { particular purposes such as leaving } \\
\text { a message or having a call returned. } \\
\text { follow appropriate format in } \\
\text { borrowinglending; c.g. } \\
\text { 1. Greetings } \\
\text { 2. State request to borrow } \\
\text { 3. Give reason for borrowing } \\
\text { 4. Promise to returm, Express } \\
\text { thanks }\end{array}$ & 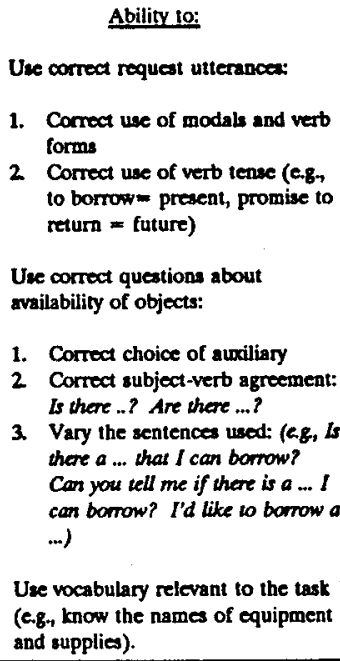 \\
\hline
\end{tabular}


Non-graded, but flexible: Ordinarily, the goals of a language teaching program are distributed according to a planned order of progression from one level to another. We could not, however, use this ordinary notion of progression for two reasons. First, the CCLC students expect to stay at the Centre for only one term. At the semester's end, they must take the CanTEST, expecting to pass on the first try. Most students, in fact, do so, regardless of their starting proficiency level. In order to reflect this characteristic of our teaching situation, we designed the syllabus around only one set of goals, the same for all classes regardless of their starting proficiency levels. To ensure that no group is handicapped, however, we chose projects (e.g., drawing up a class profile, presenting an oral report, writing a report) that could be done by multilevel classes proceeding at different rates. For example, in the reading course, we designed the activities so that slower learners could get by with reading fewer articles or could take a longer time to read their prescribed articles. For difficult reading materials such as scientific reports we designed the activities so that the students would first read and understand easier materials (such as newspaper reports on the same issue) before proceeding to excerpts from the genuine articles.

\section{The Design of the Pedagogical Activities}

We designed the pedagogical tasks to be modular, project oriented, theme based, and CanTEST-sensitive. Pedagogical tasks are classroom activities designed to promote the knowledge and skills necessary to handle real world tasks or placement tasks.

Modular: We organized our pedagogical tasks into two to fourweek modules. A module is defined as a series of one hour-long lessons on the same theme. The Class Profile module described above is a series of 3 one-hour lessons, all leading towards the creation of a descriptive paragraph on the class. The modules are designed to be used independently from one another and in any order.

Project oriented: The classroom activities to implement the syllabus were designed around concrete projects that the students can complete only after they have gone through different stages of gathering and exchanging information. Examples of such projects are making charts and tables to explain an issue, constructing a floor plan of an office complex, understanding certain facets of an issue, and finding out underlying cultural themes.

Theme-based: Earlier versions of the CCLC curriculum were thematic (e.g., Scoggan, 1985); that is they were developed around 
themes and topics that are likely to be frequently discussed in the living and workplace environment of the learners in Canada. We retained this thematic character but reduced the number of categories to only three: a) Placement themes-topics to do with providing a supportive environment for the trainees in Canada, b) Canadian themes-topics to do with the common concerns of Canadians (e.g., health and nutrition) and c) World themes-topics to do with the preoccupations of the world at large such as environmental concerns (i.e., pollution, women's issues). Table 3 lists these issues and themes.

TABLE 3

Taxonomy of Themes

\begin{tabular}{|c|c|c|}
\hline PLACEMENT THENES & CANADLAN THEMES & WORID ISSUES \\
\hline $\begin{array}{l}\text { Plyyical exvironment (e.g. Woricplace, } \\
\text { Living Acoommodations. } \\
\text { Neighbourhood Facilities) }\end{array}$ & $\begin{array}{l}\text { Fumily L Lifentyles (e.z., Marriage, } \\
\text { Caild Rearing, Divorce, Sex } \\
\text { Equality) }\end{array}$ & $\begin{array}{l}\text { Emviroanons (Conservation, Pollution, } \\
\text { Population Growth, Food Production) }\end{array}$ \\
\hline $\begin{array}{l}\text { People (Colleaguea. } \\
\text { Supervisor } \mathbf{E} \text { Employers, "Ordinary } \\
\text { Canadians" }\end{array}$ & $\begin{array}{l}\text { Health (e.g., Dies, Nutrition, Exercise, } \\
\text { Medicare) }\end{array}$ & $\begin{array}{l}\text { Women's ineses (Equaliny in the } \\
\text { Workpiace, Achicvementw, Problems, } \\
\text { Training, Redress) }\end{array}$ \\
\hline \multirow{6}{*}{$\begin{array}{l}\text { Plscemeal Requiremeats (e.g., Factors } \\
\text { Promoting Success, Problems in the } \\
\text { Workplace, Interpersonal Relationsbips, } \\
\text { Responsibilities and Rights) }\end{array}$} & $\begin{array}{l}\text { Aging (e.g, Lifertylea, Care, Joys, } \\
\text { Problems) }\end{array}$ & $\begin{array}{l}\text { Addiction and Rehabilitstion (Smoking, } \\
\text { Drugs, Alcohol) }\end{array}$ \\
\hline & $\begin{array}{l}\text { Education (Attitudes, Expectations, } \\
\text { Problems, Alternatives) }\end{array}$ & $\begin{array}{l}\text { Modicine (Medical Breakthroughs, } \\
\text { Diseases, Cures, Altemative Medicinea) }\end{array}$ \\
\hline & $\begin{array}{l}\text { Work (e.g., Safety in the Workplace, } \\
\text { Work Ethics) }\end{array}$ & $\begin{array}{l}\text { Tectuototy (Inventions, Impact on } \\
\text { Society, Social Respousibilitie) }\end{array}$ \\
\hline & $\begin{array}{l}\text { Cunedias lawe (e.g., Ideals, Valuea. } \\
\text { Altitudes, History, Geography, } \\
\text { Government) }\end{array}$ & Eubical irasca (Abortion, Euthanasia) \\
\hline & $\begin{array}{l}\text { Juetiox (e.g., Reporting crime, } \\
\text { Redressing Wrongs, Law Enforcement) }\end{array}$ & \\
\hline & $\begin{array}{l}\text { Languge \& Culture (e.g.r. Bilingualism. } \\
\text { Multiculturalism, Native Rights, Arts, } \\
\text { Literature) }\end{array}$ & \\
\hline
\end{tabular}

CanTEST-sensitive: Although, in general, the washback effect of the final examination is not the guiding principle in the development of a curriculum, the importance of passing the CanTEST in the students' life had to be taken into account. The majority of the modules were designed to accommodate a reasonable amount of CanTEST-type exercises (e.g., multiple choice, true-false questions, cloze exercises). 
Communicative Approach: When the CCLC was established in 1982 , it was agreed that a communicative approach would be used (Patrie, 1982). But, although the Chinese recognized the suitability of this approach, they felt reluctant to adopt it (Burnaby \& Sun, 1989; Li, 1984; Sun, 1985; Wang, 1986). Analysis of the problem revealed their reticence to be due to several factors. One was the lack of standard methodology associated with the approach. The teachers expected to learn the approach by observing their Canadian counterparts but were confused and frustrated by the absence of one clear model to follow (Burnaby \& Sun, 1989). The game-like nature of many of the prescribed activities also did not help. Used to a methodology where learning is associated with analyzing texts, formulating rules, memorizing target elements, etc., both the Chinese teachers and students felt sceptical that learning would take place in a teaching framework where these were not used.

The Methodology: The methodology we eventually developed for the CCLC was one that combined the best of western-based communicative approaches (insistence on genuine communication as a medium for learning) and the best of traditional Chinese teaching methodologies (reliance on activities that focus on the formal structure of language: text analysis, grammatical explanations, drills, text and rule memorization). This methodology allows the teacher to lead the students through three distinct but tightly integrated phases of learning: a Preparation Phase, a Communication Phase and a Consolidation Phase, coming normally, though not exclusively, in this order. In the Preparation Phase, the teacher, first, helps the students understand the purpose and procedure of the lesson's main activity(ies). Then, he or she helps them become receptive to these activity(ies) by arousing their curiosity (e.g., predicting), by helping them marshall prior or background knowledge (e.g., brainstorming), and finally, by helping them overcome barriers to their full participation in these activities (e.g., anticipating difficult vocabulary they will encounter in the texts).

The activities in the Communication Phase include many that have already become intimately associated with the communicative approach: role playing, problem solving, games, puzzles, etc. However, to promote acquisition effectively, only those designed to meet three criteria are used. These criteria are: be genuinely communicative, be inherently repetitive, and be formulaic. Genuinely communicative is defined not just in the sense that they 
allow authentic information to be exchanged but in a stricter sense: the very act of participating in the exchange itself must be genuinely motivated. Inherently repetitive means that activity goals can only be attained through a series of repetitive acts (e.g., students can complete a chart about the class only after interviewing all their classmates using the same questionnaires). To be formulaic means that the activity is designed so that it naturally elicits a critical mass of utterances that have potential for being used repeatedly in many different occasions with little or no modifications.

The procedure of the classroom activities in our methodology may be described as follows: The students are given a communicative task to carry out, drawing on their current linguistic resources to do so. For as long as their resources suffice, no intervention takes places. Once they experience difficulties, (e.g., they are unable to find what to say or write or they do not understand what they read or hear) the resources they lack are placed at their disposal at the moment of need. For example, the teacher prompts the missing utterances without disturbing the communication flow, or seizes a convenient pause in the communication act to bring these utterances to the students' attention. When the students have completed their tasks, the teacher then leads them to participate in the activities of the Consolidation Phase.

In the Consolidation Phase the students focus on utterances that they used during the Communication Phase, particularly, those that gave them difficulties. Depending on their needs these could be fluency and accuracy-oriented activities (activities that help the students produce utterances smoothly and correctly), or various form-focusing activities such as analyzing the formal properties of these utterances (e.g., structural properties, intonation, stress properties, discourse properties), examining their content structures (e.g., the meaning of the utterances, the illocutionary force, or socio-cultural uses, the organization of knowledge) or both.

Needless to say the success of this methodology depends on how well the different phases are integrated. Integration of these phases is achieved not only by making the Preparation Phase focus upon getting the students receptive and ready to do the activities of the Communication Phase. It is also achieved by making the Consolidation Phase dependent upon what difficulties may be experienced during the Communication Phase. Table 4 below contains a schematic illustration of the methodology developed for the CCLC. 
TABLE 4

The CCLC Communicative Methodology

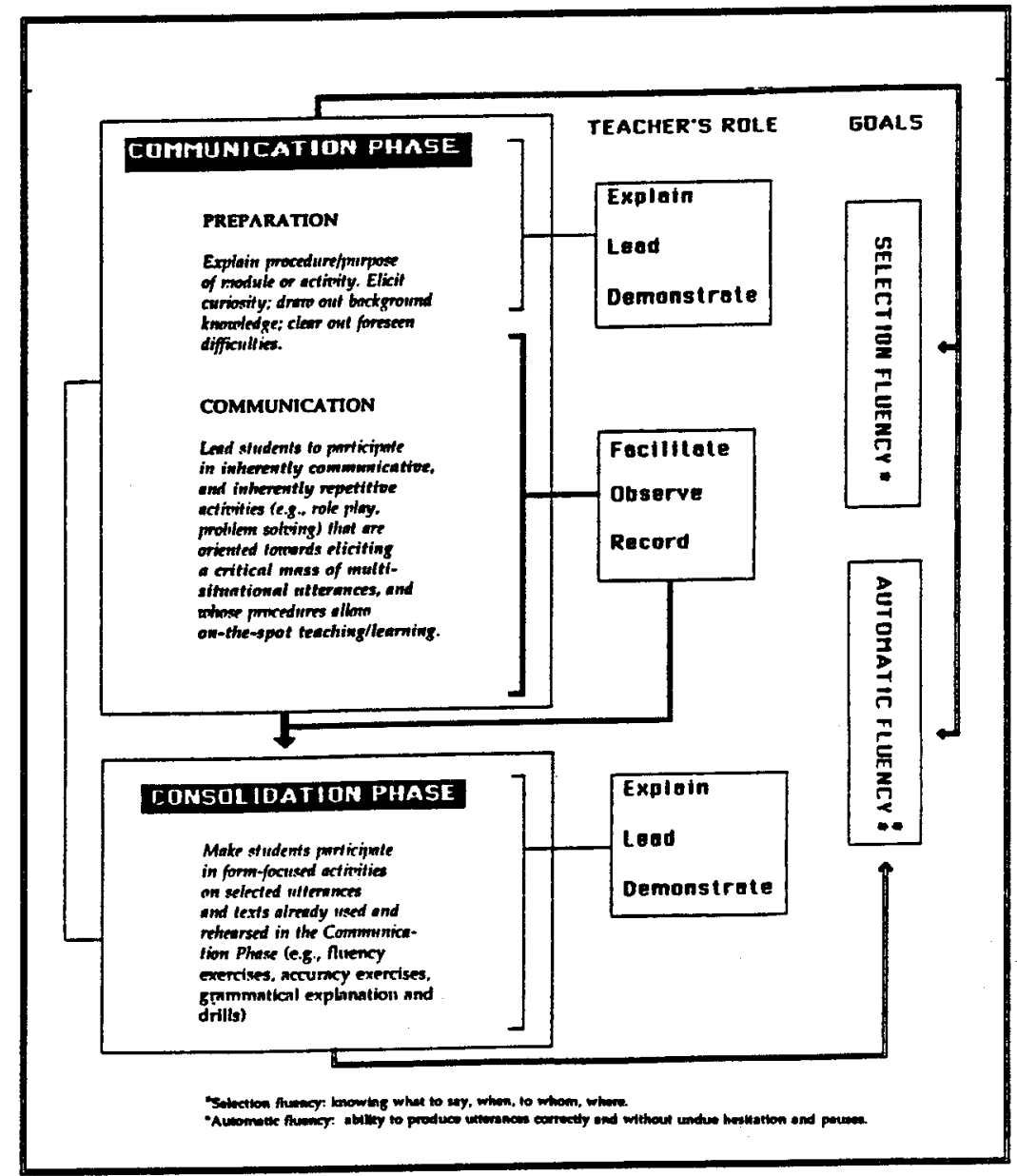


The illustration shows the three phases of a lesson and the roles the teachers must play in each. It also shows all phases aiming to promote both components of fluency: selection fluency and automatic production fluency (Gatbonton \& Segalowitz, 1988). Selection fluency is the ability to select the right thing to say, to whom, and when. Automatic production fluency is the ability to produce utterances correctly, without undue hesitations and pauses. The activities of the Communication Phase contribute to both components of fluency; those of the Consolidation Phase, primarily, to the promotion of automatic fluency and accuracy. An earlier description of this methodology is found in Gatbonton \& Gu (1991).

\section{PUTTING THE CCLC CURRICULUM DEVELOPMENT EXPERIENCES IN PERSPECTIVE}

Participating in curriculum development at the CCLC was a rich and rewarding experience. At every step of the way, we grappled with interesting issues that arose from its unique and challenging setting. In this section we will discuss briefly some of these issues.

Negotiating Differences: In negotiating a curriculum, it is assumed that all participants will have an equal say, each from his or her own perspective. Teacher participants are expected to bring their knowledge of the classroom situation; the administrators, their knowledge of policy and overall educational goals, etc. The students come with their needs and expectations; the curriculum experts, their knowledge of the theory and practice of curriculum development and language learning. If these participants have differing perceptions of any aspects of the curriculum or of the negotiation process itself, it is understood that they will resolve their differences through actual negotiations. Each participant starts with certain positions but expects these to be modified as everyone defines the compromises he or she is willing to take.

When we began $C D$ at the Centre we had no reason to believe that this process would not work. We were fully aware that our team consisted of two groups of teachers with widely differing cultural backgrounds and teaching/learning experiences. Nevertheless, we viewed these differences as simply one more set in a list of differences to be "worked out" during the discussions. It did not take long for us to see the flaw in our assumption, although our becoming sensitized to this problem came from a rather unexpected source. As in any $C D$ project we chose as forum for resolving 
differences the $C D$ "meeting". Despite efforts to promote equal participation from the Canadian and Chinese participants, however, we found these meetings to be consistently heavily dominated by Canadians. The Chinese remained withdrawn and passive, participating little except when directly asked to join in; and even then carefully avoiding open acceptance or rejection of any of the decisions taken. While, initially, the low level of Chinese participation could be attributed to inexperience in dealing with Canadians, it became clear that this explanation failed when the situation persisted even after everyone had already established good rapport with one another in other areas.

Analysis of this problematic situation revealed two sources. The first was the two groups' differing culturally-bound perceptions about the role of meetings itself. To the Canadians a meeting was where consensus was formed. People came to them with undefined ideas but expected these to be altered, expanded, or made sharper through negotiations and compromises. To the Chinese, the meeting functioned primarily as a forum where decisions, already previously taken elsewhere, were made public. Participation in meetings was governed by social constraints, many springing from hierarchical and status considerations; e.g., people in authority are expected to speak before ordinary members. Thus, the very instrument that we assumed to be effective in ironing out the differences between the two groups; namely, the curriculum development meetings, was itself the source of the problem.

To deal with this problem, we negotiated a compromise procedure for these meetings. We informally adopted a two-tier meeting, with the first dedicated to presenting and discussing proposals and counter proposals without taking any firm decisions on any of them; the second, to making these decisions. Between these two sessions, we approached the teachers in small groups or individually so that we could make sense of their real reactions to the proposals. During the second session, we helped coax these reactions out for discussions so that they could feature in everyone's final decisions.

The other problem derived from the goal of preparing the Chinese trainees to work or study in Canada. By taking this goal, the program automatically placed the Chinese teachers on an unequal footing with their Canadian counterparts. Their lack of experience in $C D$ (this activity is done at the ministerial level in China) already placed them on a less-able-to-contribute-position. In addition, their unfamiliarity with the trainees' future work or study contexts in Canada excluded them from being legitimate evaluators 
of the curriculum goals. Had the curriculum been designed to prepare the students to use English in China, the Chinese teachers alone would have had this evaluative role and as such would have been in a position to be equal or, at least, important contributors to the negotiation process itself.

In many important respects, our decision to adopt a combined communicative methodology was an attempt to redress the situation. When we combined the salient features of a western-based communicative approach with the form focusing features of Chinese teaching methodology, we hoped to form a methodology that placed the two groups of teachers on a more or less equal footing. In a combined methodology, the Canadians would be in a position of advantage with regards to conducting communication activities but not with regards to conducting Chinese style form-focused activities. The Chinese, on the other hand, would be comfortable with formfocused teaching but not with communicative teaching. Moreover, since the combined methodology would now be larger than the sum of its parts both groups would have aspects of it to learn together from scratch.

The issue of equality in the potential contribution of all participants in $C D$ negotiations is usually not raised in current $C D$ literature, possibly because the need has never been felt. In most $\mathrm{CD}$ projects done in a western setting, the participants are more or less in positions to deliver equivalent contributions. As more $C D$ projects are conducted in settings such as China, it may become imperative to add this issue to the list of theoretical concerns that need further investigation.

Choosing the Unit of Organization: Long $(1985,1990)$ argues on theoretical grounds for choosing tasks as the primary unit of syllabus organization. In our case, the decision to focus on tasks was also based on practical considerations. As already mentioned above we only have about 15 weeks to bring our students to the high proficiency level they need in English. By focusing on tasks, we felt we could ensure coverage, at least, of the students' basic functional needs while in Canada. Since our knowledge of $C D$ development and design is still inadequate to allow us to decide with certainty the full range of functions, notions, and structures we should expose our students to, we felt it would have been risky to do otherwise.

Selection of the Tasks: Success in designing a task-based syllabus depends on selecting appropriate tasks and sequencing them 
(Candlin, 1987). Current CD literature, however, offers little guidance on task selection and sequencing. To determine the tasks in each of our syllabi, we drew from needs surveys designed specifically for our program (Chase \& Marshall-Smith, 1990) as well as others designed for programs with clientele similar to ours. We found, however, that these surveys could, at best, only supply us with indications of global areas of needs (e.g., trainees would attend seminars, present reports and interact with office staff). For finer details (e.g., Do they ask questions, present opinions, disagree or agree with others during a seminar?), we could proceed only by consulting our own intuitions and checking them out against the intuitive judgement of others. For example, to prepare the initial taxonomy of tasks for the curriculum, we took each area identified in the needs surveys and subjectively spelled out their details. Later, we presented the detailed taxonomy to other Canadian and Chinese teachers who had already taught or were currently teaching at the CCLC and instructed them to modify, add to, or supplement the list. Later, we revised the list and asked again another set of teachers to examine it. We asked these teachers to indicate the tasks they believed should be handled at the CCLC, at the Regional Orientation Centres or ROCs (Trainees go to the ROCs when they reach Canada for briefing), and at the Chinese institutions that the trainees go to before entering CCLC. In yet another stage, we asked teachers currently teaching at the CCLC to indicate which of the set of tasks already chosen for the Centre could be handled in fifteen weeks.

To sum up, to select our tasks, we used information gleaned from the needs analyses as a starting point and refined it on the basis of collective intuition. In terms of what implication this has for $C D$ in general, this experience calls attention to the need to develop better instruments to measure needs at a finer level.

Authenticity of Tasks: A central issue in designing task basedsyllabi is task authenticity (Clarke, 1989, pp. 83-84). How faithful to the real tasks should the classroom activities be? Current $\mathrm{CD}$ literature reveals varying stands on this, with some claiming that classroom activities should duplicate the real world as much as possible and others claiming that they need not do so. For our part, we found distinguishing placement tasks (activities the students have to do in the real world) from pedagogical tasks (learning activities in the classroom) a useful first step. It allowed us to see that the issue of authenticity is relevant only to pedagogical tasks (placement tasks are always authentic). It also allowed us to 
examine the characteristics of real world tasks separately from those of pedagogical tasks and then determine whether there is a need for a one to one match between the two. Our conclusions have been that pedagogical tasks may sometimes be the same as real world tasks (e.g., to help students write a $\mathrm{CV}$, they are asked to write a $\mathrm{CV}$ in the classroom) but there is no inherent need for them to be always so, as long as certain conditions are met. These conditions are 1) the participants themselves have real control of the flow, direction, and nature of the conversations; create their own intentions; and select the means with which to express them; 2) that the participants experience the tensions and pressures of real communications such as those arising from not knowing what their interlocutors would say or from having to make sense of their interlocutor's utterances under time pressure (See also Gatbonton \& Segalowitz, 1988).

Methodology: Finally, in searching for a suitable methodology for our curriculum we opted for a "combinationist" approach, integrating the promotion of acquisition through communication and the systematic promotion of fluency and accuracy through grammatical explanations and constant practice.

The idea of using a combinationist approach is not new. Although proponents of communicative approaches have relegated form-focused activities to a peripheral role, many teachers refused to concede that these would play little or no role in acquisition (especially second language acquisition). So they continued to find ways of integrating them into their communicative approaches, often doing so quietly and only in the privacy of their own classrooms. The debate surrounding Krashen's claim about the exclusive role of comprehensible input in promoting acquisition (Krashen \& Terrell, 1983), fortunately, renewed interest in this issue and helped bring it back to the forefront of theorizing in the field. To argue against Krashen's claim, language specialists and teachers looked for and found theoretical (e.g., Sharwood-Smith, 1981; White, 1986) and empirical evidence (e.g., Lightbown, Spada \& Wallace, 1980) against the adequacy of comprehensible input and for the necessity of including form-focused activities in promoting acquisition.

Unfortunately, at the time we were searching for our methodology even the renewed interest on this issue had not yet led to many concrete proposals on how the combination could best be effected in the classroom. The only model readily available was one we can call a formal instruction to communication model (FI$\mathrm{COM}$ ). This model sees the progression of classroom activities as 
going from focusing on the form of utterances to creating a communicative contexts for the use of these utterances. The model is exemplified in the works of teachers who have taken Rivers and Temperley (1978)'s two-stage process of learning to mean creating classroom activities that proceed from giving, first, grammatical explanations and focused practice (skill getting) then engaging the students in real communication (skill using). It is also exemplified in the works of Paulston (1971) who proposed that drills should proceed from mechanical to meaningful to communicative. CelceMurcia and Hilles (1988) present a more recent version of this model.

In searching for a combined methodology for our curriculum we, of course, examined the suitability of this model. However, after long and careful deliberation, we decided that, since we opted for a task-based syllabus design, this model would not be suitable. We needed another model that preserved the primacy of communication as the means of promoting acquisition. Such a model should ensure that the communication needed to perform the targeted tasks would become the core of the classroom activities, with grammatical explanations and drills being used only to facilitate that communication. Though it incorporates a communicative component, the FI-COM model is still primarily focused on promoting grammatical competence. Within this model, decisions about what to do in the classroom are still governed by what grammatical knowledge should be explained and drilled. As stated above, teaching begins with the presentation of the grammatical points. Only after these points have been well understood and practised in controlled contexts, are the learners given free and genuine communicative contexts in which to use their newly acquired knowledge.

Having decided not to use the FI-COM model, we looked for alternatives. Before working as a curriculum consultant for the Canada-China project the first author had developed a set of materials for teaching beginners (Gatbonton, 1988) using a model that viewed the progression of classroom activities in the direction opposite to what was followed in the FI-COM model; namely, from communication to formal instruction (COM-FI). We examined this model more closely as a framework for developing the communicative methodology we wanted. We found the model viable if we viewed the teaching process as comprising of two phases: a Communication Phase and a Consolidation Phase. The Communication Phase is defined as one where genuine interactions could be encouraged; the Consolidation Phase as one where focused practise 
on and careful analysis of the formal properties of essential utterances can be held. By imposing the threefold criterion of genuinely communicative, inherently repetitive, and formulaic (as discussed above) on communication activities used in the Communication Phase, we could make this phase effective in promoting the learning and rehearsal of utterances needed by the learners. Finally, by requiring that the Consolidation Phase be dependent on the Communication Phase for its aims and procedure we could make this phase not just an artificially tagged on component of our methodology but an integral part of it.

Methodological concerns are central to curriculum design. In particular, because of the current popularity of task-based syllabi, the issue of what language teaching methodology is best suited for this type of design is a timely topic. In this paper we have discussed some of the problems we encountered (and solutions) in choosing the appropriate methodology for our task-based curriculum. It is hoped that the issues raised here are useful to curriculum developers everywhere who have to make decisions about similar methodological concerns.

\section{THE AUTHORS}

Elizabeth Gatbonton worked as a curriculum consultant for Saint Mary's University (Halifax)'s Canada-China Language Centre in Beijing from 1989 to 1992. In August of this year she was appointed Assistant Professor at the TESL Centre of Concordia University, Montreal.

Gu Guijing, Associate Professor of English at Beijing Normal University in Beijing, joined the Canada-China Language Centre in 1987. A year later, she went to Carleton University, Ottawa, to do a TESL Certificate program. Upon her return to the Canada-China Language Centre she became Head Teacher of the Chinese faculty, a post she occupied until her appointment as the Chinese Curriculum Consultant in 1989. She has taught English for more than 30 years and has written books and articles in Chinese and English on second language teaching and learning in China.

\section{REFERENCES}

Burnaby, B., Cumming, A. \& Belfiore. M. E. (1986). Formative evaluation report of the China/Canada language and cultural program. Toronto: Ontario Institute for Studies in Education. 
Burnaby, B. \& Sun, Y. (1989). Chinese teacher's views of western language teaching: Context informs paradigms, TESOL Quarterly, 23(2), 219-238.

Brinton, D. M., Snow, M. A. \& Wesche, M. B. (1989). Content-based second language instruction. New York: Newbury House Publishers.

Candlin, C. (1987). Towards task-based language learning. In C.N. Candlin \& D.F. Murphy, (Eds.), Language learning tasks. Lancaster Practical Papers in English Language Education. Englewood Cliffs, N.J.: Prentice-Hall International.

Canseco, G. \& Byrd, P. (1989). Writing required in graduate courses in business administration. TESOL Quarterhy, 3(2), 305-316.

Celce-Murcia, M. \& Hilles, S. (1988). Techniques and resources in teaching grammar. Oxford: Oxford University Press.

Chase, M. \& Marshall-Smith, S. (1990). From China to Canada: Preparation, placement, and support of CIDA-sponsored trainees. Report presented to the Canada-China Language and Culture Program. Saint Mary's University, Halifax, Nova Scotia.

Clarke, D. F. (1989). Communicative theory and its influence on materials production. Language Teaching. The international abstracting journal for language teachers and applied linguists. (April, 1989).

Des Brisay, M. (1991). The Canadian Test for Scholars and Trainees (CanTEST). Ottawa: The Ottawa University.

Dionne J. P., Cray, E., \& Huot, D. (1988). Mid-term project evaluation, Canada/China language and cultural programs. (Bridging project/Regional Orientation Centres). A Study prepared for the Canadian International Development Agency.

Gatbonton, E. (1988). ACCESS to fluency: Fluency/accuracy promoting communication activities for adult second language learners. Manuscript.

Gatbonton, E. (1990). Curriculum development at the Canada-China Language Centre: The history and future of the English Language Teaching Curriculum. Revised version: January 1990. Report submitted to Saint Mary's University, Halifax.

Gatbonton, E. (1992). English for visiting scholars and trainees. Vol. 1: The CCLC oral English course. Teacher's Manual and Student Workbook. Manuscript.

Gatbonton, E. \& Gu, G. (1991). The Canada-China English language teaching curriculum. Revised version. Beijing: Canada-China Language Centre. Manuscript.

Gatbonton, E. \& Segalowitz, N. (1988). Creative automatization: principle for promoting fluency within a communicative framework. TESOL Quarterly, 22(3), 437-492.

Graham J. G. \& Beardsley, R. S. (1986). English for specific purposes: Content, language and communication in a pharmacy course model. TESOL Quarterly, 20(2), 227-245.

Horowitz, D. M. (1986). What professors actually require: Academic tasks for the ESL classroom. TESOL Quarterly, 20(3), 445-462.

Hutchison, T. \& Waters, A. (1987). English for specific purposes. A learning centred approach. New York: Cambridge University Press.

Johns, A. (1981). Necessary English: A faculty survey. TESOL Quarterly, 15(1), 5157.

Johnson, R. K. (1989). The second language curriculum. Cambridge: Cambridge University Press.

Krashen, S. \& Terrell, T. (1983). The natural approach Hayward, Ca: Alemany Press.

Li, X. (1984). In defense of the communicative approach. ELT Journal, 35(1), 2-13. 
Lightbown P., Spada, N. \& Wallace, R. (1980). Some effects of instruction on child and adolescent ESL Learners. In Scarcella, R. \& S. Krashen (Eds), Research in second language acquisition. Rowley, Ma.: Newbury House.

Long, M. (1985). A role for instruction in second language acquisition: Task-based language teaching. In $\mathrm{K}$. Hyltenstan \& $\mathrm{M}$. Pienemann, (Eds.), Modelling and assessing second language acquisition. Clevedon, Avon: Multilingual Matters.

Long, M. (1990). Task, group, and task-group interactions. In S. Anivan (Ed.), Language teaching methodology for the nineties. Singapore: Singapore University Press for SEAMO Regional Language Centre, 31-50.

Mackay, R. A. \& Mountford, A. J., Eds. (1978). English for specific purposes. London: Longman.

Martin, I. \& Sun, Y. (1987). Phase two evaluation study. Report presented to the China Project Office.

Mohan, B. (1986). Language and content. Reading, Mass: Addison-Wesley Publishing Company.

Nunan, D. (1988). Syllabus design. Oxford: Oxford University Press.

Ostler, S. (1980). A survey of academic needs for advanced ESL. TESOL Quarterly, 14(4), 489-502.

Patrie, J. (1982). Needs assessment, policy statements, and recommendations: a preliminary report. Manuscript.

Prabhu, N. (1987). Second language pedagogy. Oxford University Press.

Paulston, C. B. (1971). Structural pattern drills: a classification, Foreign Language Annals, 4, 187-193.

Rivers, W. \& Temperley, M.S. (1978). A practical guide to the teaching of English. Oxford: Oxford University Press.

Sharwood-Smith, M. (1981). Consciousness-raising and the second language learner. Applied Linguistics, 7.

Scoggan, J. (1985). Canada/China language training centre curriculum outline. Beijing: Canada/China Language Training Centre. Faculty of English. University of International Business and Economics.

Snow, M. A., Met, M., \& Genesee, F. (1989). A conceptual framework for the integration of language and content in second/foreign language instruction. TESOL Quarterly, 23(2), 201-217.

Sun, Y. (1985). The communicative approach: Our debt and obligation. ELT in China. Papers presented at the International symposium on Teaching English in the Chinese Context. Beijing, China: Foreign Language Teaching and Research Press.

Tanachanan, P. (1983). A self-appraising English syllabus in EFL country. In Read, J. (Ed.), Trends in language syllabus design. Singapore: Singapore University Press for SEAMO Regional Language Centre.

Wang, K. (1986). Teaching English as a foreign language in China. TESL Canada Joumal, 4, 153-160.

White, L. (1986). Against comprehensible input: The input hypothesis and the development of L2 competence. Applied Linguistics, 7.

Yalden, J. (1987). Principles of course design for language teaching. New York: Cambridge University Press.

TESL CANADA JOURNAL/REVUE TESL DU CANADA 